\title{
BMJ Open Potential impact of intervention strategies on COVID-19 transmission in Malawi: a mathematical modelling study
}

\author{
Tara Mangal (D) , ${ }^{1}$ Charlie Whittaker, ${ }^{1}$ Dominic Nkhoma, ${ }^{2}$ Wingston Ng'ambi, ${ }^{2}$ \\ Oliver Watson (D) , ${ }^{1}$ Patrick Walker, ${ }^{1}$ Azra Ghani, ${ }^{1}$ Paul Revill, ${ }^{3}$ Timothy Colbourn, ${ }^{4}$ \\ Andrew Phillips, ${ }^{5}$ Timothy Hallett, ${ }^{1}$ Joseph Mfutso-Bengo ${ }^{2}$
}

To cite: Mangal T, Whittaker C, Nkhoma D, et al. Potential impact of intervention strategies on COVID-19 transmission in Malawi: a mathematical modelling study. BMJ Open 2021;11:e045196. doi:10.1136/ bmjopen-2020-045196

- Prepublication history and additional supplemental material for this paper are available online. To view these files, please visit the journal online. (http://dx.doi.org/10.1136/ bmjopen-2020-045196).

Extraordinary Think Tank Meeting on COVID-19, University of Malawi Health Economics and Policy Unit (HEPU). May 2020

Received 24 September 2020 Accepted 08 June 2021

Dheck for updates

(c) Author(s) (or their employer(s)) 2021. Re-use permitted under CC BY. Published by BMJ.

${ }^{1}$ Infectious Disease Epidemiology, Imperial College London, London, UK

${ }^{2}$ College of Medicine, University of Malawi, Lilongwe, Malawi

${ }^{3}$ Centre for Health Economics, University of York, York, UK ${ }^{4}$ Institute for Global Health, University College London, London, UK

${ }^{5}$ HIV Epidemiology and Biostatistics Group, University College London, London, UK

Correspondence to

Dr Tara Mangal;

t.mangal@imperial.ac.uk

\section{ABSTRACT}

Background COVID-19 mitigation strategies have been challenging to implement in resource-limited settings due to the potential for widespread disruption to social and economic well-being. Here we predict the clinical severity of COVID-19 in Malawi, quantifying the potential impact of intervention strategies and increases in health system capacity.

Methods The infection fatality ratios (IFR) were predicted by adjusting reported IFR for China, accounting for demography, the current prevalence of comorbidities and health system capacity. These estimates were input into an age-structured deterministic model, which simulated the epidemic trajectory with non-pharmaceutical interventions and increases in health system capacity.

Findings The predicted population-level IFR in Malawi, adjusted for age and comorbidity prevalence, is lower than that estimated for China $(0.26 \%, 95 \%$ uncertainty interval (UI) $0.12 \%-0.69 \%$, compared with $0.60 \%, 95 \% \mathrm{Cl} 0.4 \%$ to $1.3 \%$ in China); however, the health system constraints increase the predicted IFR to $0.83 \%, 95 \%$ UI $0.49 \%$ $1.39 \%$. The interventions implemented in January 2021 could potentially avert 54400 deaths (95\% UI 26900-97 300 ) over the course of the epidemic compared with an unmitigated outbreak. Enhanced shielding of people aged $\geq 60$ years could avert 40200 further deaths $(95 \%$ UI 25300-69 700) and halve intensive care unit admissions at the peak of the outbreak. A novel therapeutic agent which reduces mortality by 0.65 and 0.8 for severe and critical cases, respectively, in combination with increasing hospital capacity, could reduce projected mortality to 2.5 deaths per 1000 population (95\% UI 1.9-3.6).

Conclusion We find the interventions currently used in Malawi are unlikely to effectively prevent SARS-CoV-2 transmission but will have a significant impact on mortality. Increases in health system capacity and the introduction of novel therapeutics are likely to further reduce the projected numbers of deaths.

\section{INTRODUCTION}

As of 15 March 2021, the novel coronavirus SARS-CoV-2 had spread throughout every continent, with over 100 million cases and 2.5 million deaths reported worldwide. ${ }^{1}$ Case numbers in the African continent continue to rise, and until widespread deployment of

\section{Strengths and limitations of this study}

- This is the first study to date which combines country-specific infection fatality ratios (IFRs) of COVID-19 for Malawi adjusted for comorbidity prevalence and with consideration of the prevailing health system constraints and the impact of these constraints on mortality rates.

- An age-structured deterministic model was used to characterise the spread of SARS-CoV-2 throughout Malawi using the Malawi-specific adjusted IFR.

- The impacts of non-pharmaceutical interventions, novel therapeutics and hospital capacity were analysed, and the effects on incidence, mortality and hospital demand are presented.

- The IFR used as the baseline, from which we inferred the adjusted IFR for Malawi, and some key parameters used in the simulation modelling relied on data from outside sub-Saharan Africa due to the limited numbers of cases there and might therefore not be directly transferable to Malawi.

an effective vaccine, there is a critical reliance on non-pharmaceutical interventions (NPI) to reduce transmission. These measures include isolation of suspected/confirmed cases, contact tracing, social distancing, travel restrictions, face covering, school and workplace closures, and shielding of the most vulnerable. ${ }^{2-5}$

By 1 January 2021, Malawi was experiencing a second wave of infections, and additional restrictions were placed on the population. Schools and workplaces were closed in many districts; large gatherings and public events were banned; but a full lockdown has been prohibited due to concerns around the implications on vulnerable populations. ${ }^{6}$ The impact of NPI on SARS-CoV-2 transmission in Malawi depends critically on the local context such as population behaviour (including uptake of and compliance with such measures), population movement and contact patterns (Malawi is over $80 \%$ rural 
and many rely on subsistence farming) and health system capacity. $^{7}$

The impact of NPI can be summarised as a change in the effective reproduction number $R_{t}$, which represents the average number of secondary infections resulting from one infected case. Studies based on high-income countries have shown that strict interventions such as lockdown, where population movement is limited to essential travel and most public facilities and transport links are closed, have shown the most success in reducing transmission. ${ }^{34-10}$ However, major restrictions to working practices or public transport may have catastrophic implications in sub-Saharan Africa, where many have limited financial capacity to withstand income shocks and no access to social protection programmes. ${ }^{11}$ Face coverings have been recommended by WHO as one possible intervention which could reduce transmission of SARS-CoV-2 with minimal socioeconomic implications despite a lack of high-quality evidence. ${ }^{12} 13$ Nevertheless, many countries (including Canada, South Korea and the UK), have made face coverings mandatory in public spaces.

A key priority during this emerging pandemic is estimating clinical severity and health system requirements. Current oxygen capacity in hospitals may not be sufficient to give supportive care to large numbers of severe COVID-19 cases; $65 \%$ of 34 hospital wards in Malawian hospitals recently assessed had (what was considered pre-COVID-19) adequate access to oxygen and priority is now being given to scaling up access and supplies urgently. ${ }^{14}{ }^{15}$ Early studies suggest oxygen supplementation could reduce the need for mechanical ventilation and lower the risk of death. ${ }^{16}$ Additionally, several therapeutic agents, such as tocilizumab and dexamethasone, have been effective in improving patient outcomes, although none so far have been widely tested in subSaharan Africa. ${ }^{1718}$

Infection fatality ratios (IFR), defined as the number of deaths divided by the number of infections, are challenging to estimate, particularly in an emerging outbreak, due to the difficulties in identifying the true number of infected people (both asymptomatic and symptomatic). IFR are strongly dependent on age, and the majority of deaths reported early in the epidemic were among those aged over 60 years. ${ }^{19-21}$ There is also a growing body of evidence on the elevated risk of mortality with certain underlying comorbidities, such as cardiovascular disease (CVD), diabetes, chronic obstructive pulmonary disease (COPD) and infectious diseases, for example, HIV, tuberculosis (TB) and malaria. ${ }^{22-25}$ The majority of these data were reported from highincome settings, which have borne the highest burden of COVID-19 disease recorded so far. It is not yet clear how these risk factors will affect COVID-19 severity in countries like Malawi, which have a younger population overall, but a high prevalence of infectious diseases and untreated chronic conditions.

\section{Objectives}

Three objectives form the focus of this paper: (1) to predict disease severity caused by SARS-CoV-2 in the Malawian population, given its demographic structure, the prevalence of key comorbidities and health system capacity; (2) to examine the potential impact of a range of NPI that have been or could be used in Malawi; and on that basis, (3) to investigate the potential extent to which increasing health system capacity and/or providing therapeutics could contribute to reducing deaths due to SARS-CoV-2 infection.

\section{METHODS}

We present the methods in three sections that relate to each of our aims.

\section{Predictions of IFR in Malawi}

Our approach uses data on age-specific IFR from China (one of the few studies which applies demographyadjusted underascertainment corrections) and then makes adjustments based on the demography and relative burdens of diseases relevant to COVID-19 risk between China and Malawi, making assumptions about the extent to which each disease affects IFR and the extent and impact of healthcare available. ${ }^{21}$ First, we predict IFR by age under the assumption of similar availability and impact of healthcare. We then use these predicted IFR and adjust for the potential impact of a constrained healthcare system in Malawi, making assumptions on the effect of treatment on mortality rates of severe and critical cases. The predicted IFR therefore represents pooled estimates of those receiving and not receiving care.

\section{Predicted IFR with an unconstrained health system}

The prevalence of HIV (virally suppressed and unsuppressed), active TB, clinical malaria, CVD, COPD, hypertension, diabetes (types I and II), obesity (defined as Body Mass Index of $\geq 28 \mathrm{~kg} / \mathrm{m}^{2}$ according to Chinese criteria and $\geq 30 \mathrm{~kg} / \mathrm{m}^{2}$ using Malawian criteria) and malnutrition were extracted for Chinese and Malawian populations (see online supplemental figure 1 and online supplemental table 1 for data sources). We created a unified risk factor for 'metabolic syndrome', defined as the presence of at least one of the following conditions which tend to be clustered within individuals: CVD, hypertension, obesity and diabetes. The plausible range for the risks of mortality due to metabolic syndrome was taken as the outer bounds of the relative risks reported for each of the pooled conditions. Given the considerable uncertainty in these estimates along with likely differences across settings, we sample from a wide range of relative risk values for each comorbidity (online supplemental table 2).

The baseline age-distributed IFR were derived from those published by Verity et al for cases reported in mainland China, using linear interpolation on the log scale to derive values in 5-year age groups from the 10-year age 
bands reported. ${ }^{21}$ Adjusted IFR by age for Malawi were computed as follows:

1. Lognormal distributions were derived for each of the age-distributed IFR from China such that the mean matched the mean IFR, and $95 \%$ of the probability mass fell inside the reported $95 \%$ bounds. Uniform distributions were defined for the relative risks of mortality due to COVID-19 for each comorbidity covering the range described in online supplemental table 2.

2. Age-specific IFR and relative risks of mortality with comorbidities were sampled from the defined distributions.

3. Age-distributed IFR for a theoretical population with no comorbidities $\left(I F R_{a}^{*}\right)$ were computed using the sampled values as follows:

$$
I F R_{a}^{*}=\frac{I F R_{h=C h i n n a, a}}{\sum_{i}\left(r_{i} \cdot c_{i}, h, a\right)}
$$

where $I F R h_{\mathrm{h}=\mathrm{China, \textrm {a }}}$ was the sampled IFR in setting $h$ (where $h$ is China); $i$ is the index for each comorbidity; $r_{\mathrm{i}}$ is the sampled relative risk of mortality for each condition; and $c_{\mathrm{i}, \mathrm{h}, \mathrm{a}}$ is the prevalence of each comorbidity in setting $h$. All terms except relative risk values were indexed by age group $a$, assuming that there are no interactions between age and relative risk of death due to comorbidity.

4. The adjusted IFR for Malawi were then estimated using equation 2:

$$
I F R_{h=\text { Malawi,a }}=\operatorname{IFR}_{a}^{*} \sum_{i}\left(r_{i} * c_{i, h=\text { Malawi }, a}\right)
$$

5. Steps 2-4 were repeated 1000 times and the median adjusted IFR and uncertainty intervals (UIs) were calculated as the 50th, 2.5th and 97.5th quantiles from the sampled estimates.

A summary for the average IFR for Malawi was obtained by weighting the age-specific IFR by the proportion of the population in each age group, as follows:

$$
I F R_{h=\text { Malawi }}=\frac{\sum_{a}\left(N_{a} . I F R_{h=\text { Malawi }, a}\right)}{\sum_{a} N_{a}}
$$

where $N_{a}$ is the number of persons in that age group. The analysis was repeated using data on IFR from Brazil to determine whether the choice of primary data would affect the predicted IFR in Malawi.

This method assumed that the differences in IFR between settings are driven by the presence of comorbidities and differences in the age structure of the population.

\section{Predicted IFR adjusting for health system constraints}

The effect of access to and quality of healthcare was accounted for through the following additional steps:

1. Parameter sets defining the proportion of COVID-19 cases requiring different levels of hospital care (severe or critical) were generated using rejection sampling on the basis of (1) prior information from high-income settings and (2) assumptions for mortality according to disease severity with treatment (online supplemental table 3).
2. These estimates of disease severity were used in the simulation model (detailed in the following section) to simulate epidemic trajectories over 365 days without NPI, where the availability of hospital care was limited to the level currently prevailing in Malawi.

3. The induced overall IFR in Malawi, given the current healthcare system constraints at the end of the epidemic, was 'number who died of COVID-19/number ever infected with SARS-CoV-2'.

Further details are provided in the Supplementary Information.

The resulting population-level IFR predictions for Malawi were compared with China using Monte Carlo simulation. IFR values for China were sampled 1000 times from the lognormal distributions for comparison and the Kolmogorov-Smirnov (KS) test statistic was computed, producing a KS test statistic distribution.

\section{Estimates of the potential impact of NPI on transmission of SARS-CoV-2}

The COVID-19 model of Walker et al was used to make projections of the spread of SARS-CoV-2 in Malawi under a number of NPI scenarios. ${ }^{26}$ Briefly, the deterministic model comprises an age-structured Susceptible-ExposedInfected-Recovered (SEIR) compartmental framework which describes the transmission of SARS-CoV-2 through an otherwise homogenous population. The contact rates between age groups were derived from the Manicaland study in Zimbabwe (online supplemental table 4). ${ }^{27}$ Infected (and infectious) cases were classified as mild (not requiring care), severe (requiring hospitalisation/ oxygen) and critical (requiring intensive care unit (ICU) / mechanical ventilation) with the likelihood of receiving care constrained by the prevailing health system capacity. We assumed that not all critical cases required mechanical ventilation, but for those that do, access to an ICU bed also indicates availability of mechanical ventilation. In each infected stage, there was a probability of death, derived from multinational analyses from data in China, the UK and the USA. It was assumed that hospitalised cases would not contribute to transmission. In the case of a person needing care but the health system capacity being exhausted, the person was exposed to a risk of death consistent with no care being received (online supplemental table 5).

\section{Epidemic setting}

We assumed $R_{t}=2$, which was a central value for the estimates of $R_{t}$ in Malawi immediately prior to the second wave and varied this between 1.5 and 2.5 to reflect the uncertainty in this assumption. ${ }^{28}$ At the start of the simulation, 20 cases were seeded in age groups 35-54, reflecting the ages of those who were most likely to be working or travelling and acquired infection. The population was considered to be fully susceptible during this simulated second wave due to waning immunity following infection in the first wave, along with the emergence of 
Table 1 List of the interventions under consideration along with their implementation in the model

\begin{tabular}{|c|c|}
\hline Strategy & Implementation \\
\hline Current situation & $\begin{array}{l}\text { Assumed to be in place at the start of the outbreak } \\
\text { Workplaces are closed; public events are banned; restrictions on } \\
\text { gatherings are in place; public transport is reduced. } \\
\text { Consider these strategies as a bundle equating to a combined } \\
\text { reduction inR of } 24 \% .^{9} \\
\text { Dates and details of individual non-pharmaceutical interventions } \\
\text { are reported by OxCGRT. }\end{array}$ \\
\hline $\begin{array}{l}\text { Enhanced shielding: } \\
\text { Current situation, plus } \\
\text { shielding of those aged } \geq 60 \text { years }\end{array}$ & $\begin{array}{l}\text { Reduce contact rates by } 60 \% \text { for populations aged } \geq 60 \text { years in } \\
\text { addition to the reduction in } R_{t} \text { mentioned previously. } \\
\text { It is implemented after a trigger is reached.* }\end{array}$ \\
\hline $\begin{array}{l}\text { Lockdown: } \\
\text { Current situation plus: } \\
\text { Stay-at-home requirements } \\
\text { School closures } \\
\text { Enforcement of social distancing in excepted businesses } \\
\text { Prohibition of public transportation } \\
\text { Prohibition of all gatherings outside household }\end{array}$ & $\begin{array}{l}\text { Consider that this bundle equates to a sustained reduction in } R_{t} \text { of } \\
42 \% .{ }^{9} \\
\text { It is implemented after a trigger is reached. }{ }^{*}\end{array}$ \\
\hline
\end{tabular}

*The trigger date for interventions to be applied was when the rate of death exceeded 1.0 COVID-19 deaths per 100000 population per week.

newer strains capable of evading pre-existing immune responses. $^{29}$

\section{NPI strategies}

The NPIs that were in place at the start of the second wave are summarised in table 1 . We additionally considered the potential impact of shielding those aged $\geq 60$ years and lockdown. The duration of lockdown varied between 6 and 24 weeks, whereupon the previously implemented intervention strategies were resumed. The trigger day for the implementation of NPI was when the rate of deaths exceeded 1.0 death per 100000 population per week.

Face coverings were analysed as an incremental intervention on top of the existing measures, and we explored a full range of values for efficacy and proper usage, assuming that the current measures in place remained for the duration of the simulation. We did not distinguish between household and non-household transmission and assumed adherence and efficacy jointly reduced the risk of transmission to the whole population.

The low numbers of deaths reported to date in Malawi coupled with the high potential for under-reporting make formal calibration to surveillance data problematic. We opted, therefore, to present a hypothetical scenario using plausible estimates for transmission rates in this setting and incorporating uncertainty around key assumptions.

We ran each simulation 1000 times over 365 modelled days using the sampled parameter sets for disease severity (see previous discussion). The outcomes of each intervention on the daily number infected, health system requirements (broken down by severity) and deaths are presented.

\section{Estimates of the impact of increasing health system capacity}

The projected impact of increasing the number of nonintensive care hospital beds plus availability of oxygen and the introduction of a novel therapeutic agent were examined, assuming that the current intervention strategies would remain in place indefinitely. We simulated an increase in hospital bed capacity (plus access to oxygen) by up to $100 \%$ from the trigger day of when the rate of deaths exceeded 1.0 deaths per 100000 population per week, presenting the resulting impact on the cumulative number of deaths projected to occur over the epidemic. Additionally, the impact of a novel therapeutic agent was analysed, assuming a proportional reduction in mortality for severe and critical cases $(0.65$ and 0.8 , respectively, which is of the same order of magnitude as indicated in the Randomised Evaluation of COVID-19 Therapy (RECOVERY) trial on dexamethasone, but the modelled agent is hypothetical) applicable to all age groups. ${ }^{17} \mathrm{We}$ assumed that the therapeutic agent could be administered to those in need even if hospital beds or ICU beds were not available.

All analyses were conducted in $\mathrm{R}$ statistical software V.3.6.3 (https://www.r-project.org/).

\section{Data sharing agreement}

Source code and supporting documentation for the SEIR model are available online (https://githubcom/mrc-ide/ squire). All data used in the analyses are publicly available and sources have been listed for each.

\section{Patient and public involvement}

Patients and/or the public were not involved in the design, conduct, reporting or dissemination plans of this research.

\section{Role of the funding source}

The funders of this study had no role in study design, data analysis, data interpretation or writing of the report. All 


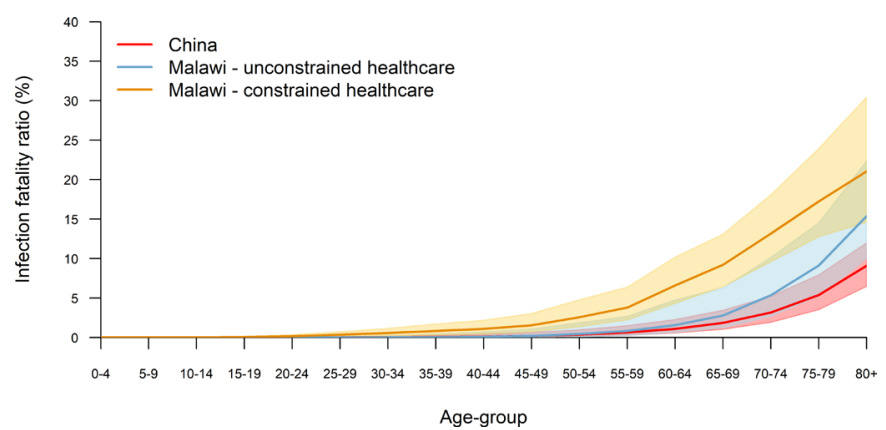

Figure 1 Predicted infection fatality ratios for the Malawian population with unconstrained and constrained healthcare (according to current health system capacity) compared with estimates reported from China.

authors had access to all data in the study and accept final responsibility for the decision to submit for publication.

\section{RESULTS}

\section{Predictions of infection fatality ratios in Malawi}

Under the assumption of similar healthcare availability, the predicted age-specific IFR for Malawi are higher for every age group than those reported in China. However, the predicted population-weighted IFR is lower (IFR $0.26 \%, 95 \%$ UI $0.12 \%-0.69 \%$, compared with $0.6 \%$, $95 \%$ CI $0.40 \%$ to $1.30 \%$ in China) due to the younger average age of the population (figure 1). Incorporating health system constraints through the simulation model results in significantly higher age-specific IFR for Malawi $(\mathrm{p}<0.05$, KS test for all age groups), although the population-weighted estimate is not significantly different from that reported for China (overall IFR $0.83 \%$, 95\% UI $0.49 \%-1.39 \%$ ). When using the Brazil data, the adjusted population-weighted IFR for Malawi assuming no health system constraints is $0.48 \%$ (95\% UI $0.33 \%-0.64 \%$ ), compared with $0.26 \%$ (95\% UI $0.12 \%-0.69 \%$ ) when using the Chinese data (online supplemental figure 2).

\section{Estimates of the potential impact of NPI on transmission of SARS-CoV-2}

The projected unmitigated scenario is presented as counterfactual, showing what could occur had no interventions been introduced (figure 2). With the current interventions in place and assumed to be in place indefinitely, we estimate approximately 54400 deaths (95\% UI 26900-97 300) could be averted over the course of the epidemic compared with an unmitigated scenario in which 134300 deaths (95\% UI 82100-222500) are projected to occur (table 2). Enhanced shielding of people aged $\geq 60$ years could avert a further 40200 deaths (95\% UI 25 300-69 700) and halve ICU admissions at the peak of the outbreak. These measures would also delay the spread of infection, shifting the peak in infections by approximately 66 days.
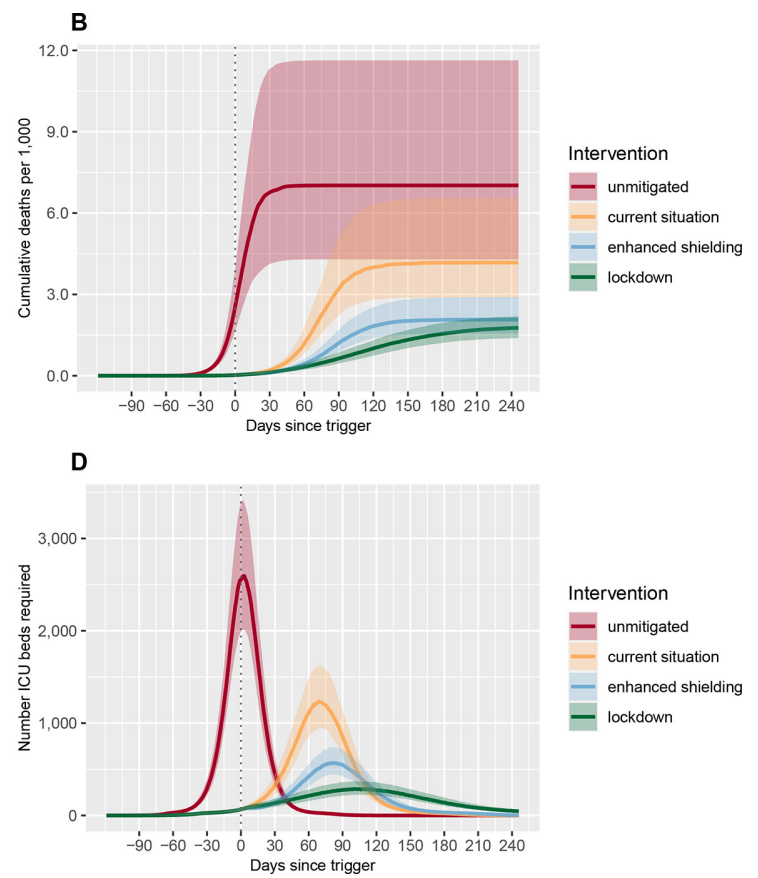
Table 2 Outputs from intervention strategies over 365 days

\begin{tabular}{lllll}
\hline & Unmitigated & Current situation & Enhanced shielding & Lockdown \\
\hline Total cases/1000 population & 769.7 & 575.3 & 499.8 & 275.0 \\
& $(668.4-872.6)$ & $(483.1-667.4)$ & $(412.4-591.4)$ & $(223.6-326.9)$ \\
Number of general hospital beds required & 40700 & 25700 & 17300 & 5700 \\
at peak & $(28000-59700)$ & $(14500-34800)$ & $(9800-26400)$ & $(3100-9900)$ \\
Number of ICU beds required at peak & 2600 & 1200 & 600 & 300 \\
& $(2000-3400)$ & $(900-1600)$ & $(400-700)$ & $(200-400)$ \\
Total deaths/1000 population & 7.0 & 4.2 & 2.1 & 1.8 \\
& $(4.3-11.6)$ & $(2.9-6.5)$ & $(1.6-2.9)$ & $(1.4-2.2)$ \\
\hline
\end{tabular}

All values are medians of 1000 simulations using the sampled parameter sets for disease severity. Numbers of hospital and ICU beds are rounded to the nearest 100 .

The predicted age distribution of infected people at tions occur in the younger ages $(<20$ years) which make up $>50 \%$ of the population and have high contact rates (online supplemental figure 3 ), although only $1.3 \%$ of deaths occur in that group. There is, however, considerable uncertainty around the prevalence and impact of comorbidities such as HIV and malnutrition in these age groups. The majority of projected deaths occur in those aged over 70 years.

Of the mitigation strategies modelled, long-term lockdown has the largest impact, bringing the infection rate down to 275 infections per 1000 population $(95 \%$ UI 224-327 per 1000 population) and the mortality rate to 1.8 deaths per 1000 population (95\% UI 1.4-2.2 per 1000 population, equivalent to 33800 deaths, $95 \%$ UI 26600-41 900; table 1). Applying lockdown over 6, 12 and 24 weeks delays the peak incidence, reducing the size of the outbreak and maintaining hospital requirements below capacity, which in turn reduces mortality rates (online supplemental figure 4). The impact of each intervention with $R_{t}=1.5$ and 2.5 is shown in online supplemental table 6).

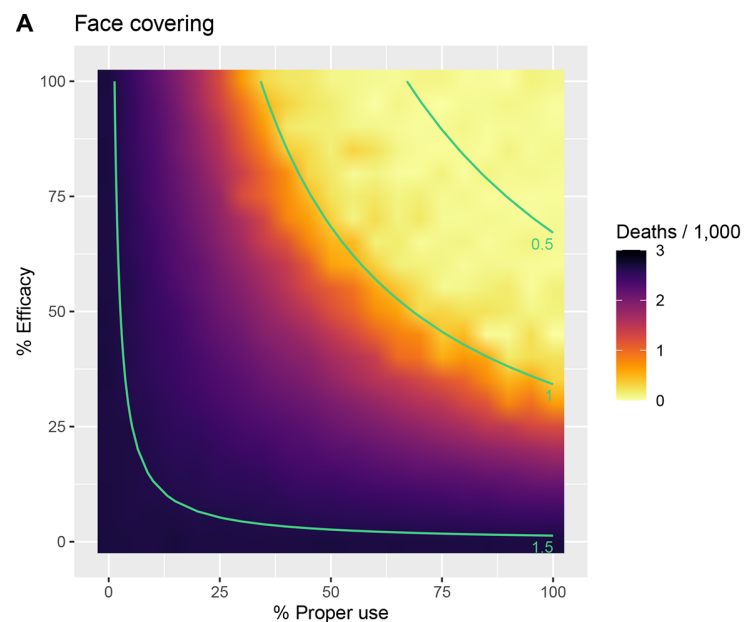
the peak of the epidemic shows that the majority of infec-

With current interventions in place, coverage of face coverings would need to exceed $60 \%$ ( $30 \%$ with shielding implemented simultaneously) with a minimum efficacy of $50 \%$ in order to reduce the projected $R_{t}$ to below 1 (figure 3).

\section{Estimates of the impact of increasing health system capacity} Increasing capacity for non-intensive care (general hospital beds with oxygen availability) by $50 \%$ reduces the projected mortality rate to 3.7 deaths per 1000 population (95\% UI 2.8-5.3) compared with 4.2 (95\% UI 2.9-6.5) under the current scenario (online supplemental table 7). Doubling hospital and oxygen capacity could marginally reduce this further to 3.5 deaths per 1000 population (95\% UI 2.8-4.7). Introducing a novel therapeutic agent that is capable of reducing mortality by 0.6 for severe cases and by 0.85 for critical cases, in combination with a $50 \%$ scale-up in hospital capacity, reduces projected deaths to 2.5 deaths per 1000 population (95\% UI 1.9-3.6, figure 4).

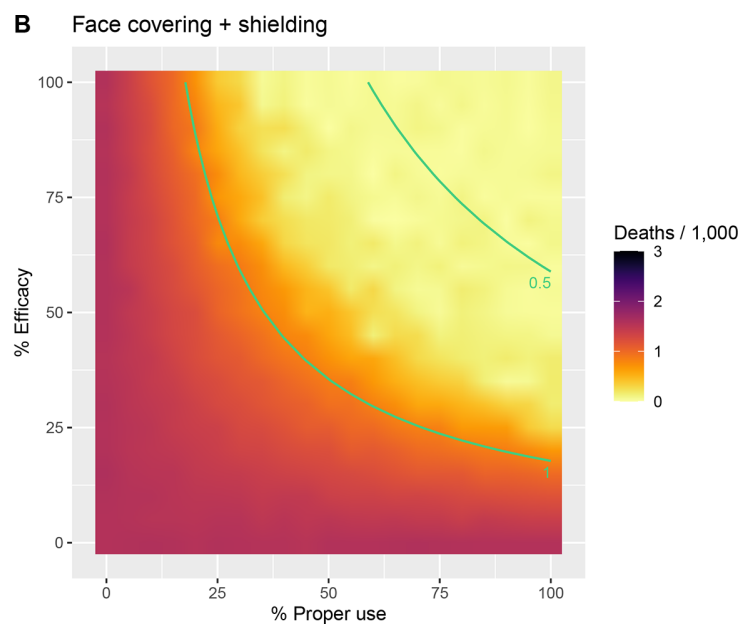

Figure 3 Impact of face covering (A) and face covering plus enhanced shielding (B) on the total number of deaths per 1000 population projected to occur over 365 days. The full range of values for \% efficacy and \% proper use (adherence) is presented. The current interventions are assumed to remain in place. The isoclines (green lines) represent the estimated $R_{t}$, given the efficacy and adherence. 


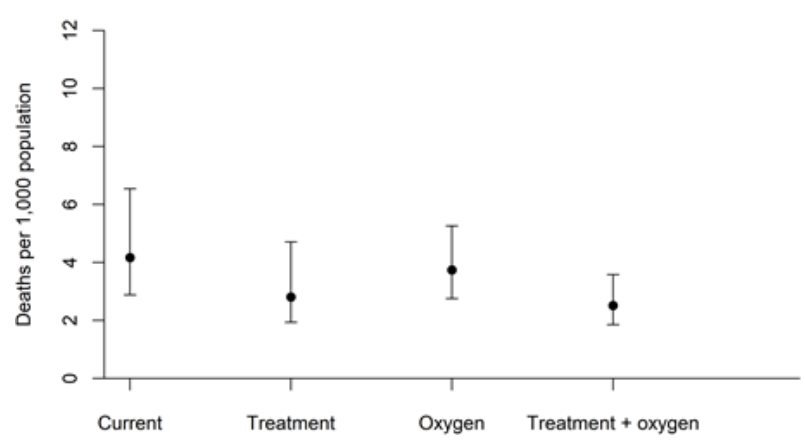

\begin{tabular}{|l|l|}
\hline Intervention & Notes \\
\hline Current & Assumes current interventions remain in place \\
\hline Treatment & $\begin{array}{l}\text { Current interventions in place plus availability of a } \\
\text { therapeutic agent for all severe/ critical cases } \\
\text { (irrespective of hospital bed availability) }\end{array}$ \\
\hline Oxygen & $\begin{array}{l}\text { Current interventions in place plus } 50 \% \text { scale-up in } \\
\text { hospital beds and oxygen availability }\end{array}$ \\
\hline Treatment + oxygen & $\begin{array}{l}\text { Current interventions in place plus } 50 \% \text { scale-up in } \\
\text { hospital beds and oxygen availability and availability of a } \\
\text { therapeutic agent for all severe/ critical cases } \\
\text { (irrespective of hospital bed availability) }\end{array}$ \\
\hline
\end{tabular}

Figure 4 Projected total numbers of deaths per 1000 population over 365 days with increases in hospital capacity (and oxygen) and a novel therapeutic agent. The points show the median of 1000 simulations, with 2.5 th and 97.5 th uncertainty intervals represented by the bars.

\section{DISCUSSION}

The results shown here give several important insights into the potential spread and severity of SARS-CoV-2 infection in Malawi and what can be done to prepare for it.

First, under the assumption of similar access to healthcare, overall population-weighted IFR are lower than the reported values for China, consistent with findings from Brazeau et al (estimates for low-income countries 0.23 , $95 \%$ prediction interval $0.14-0.42$ ) due to the younger average age of the population. ${ }^{21} 30$ As the availability of healthcare is much lower in Malawi, the overall expectation for IFR increases to $0.83 \%$, 95\% UI $0.49 \%-1.39 \%$, within the range of estimates reported across the Americas, Asia and Europe (overall IFR 0.70, 95\% CI 0.57 to 0.82, range $0.28-0.89) .{ }^{31}$ Estimates of mortality in Uganda follow a similar trend, with a lower predicted disease burden than the comparator regions (Europe, America and China) and the majority of risk arising indirectly due to disruptions to the health service. ${ }^{32}$ Other studies have also reported a differential risk of severe disease in African settings compared with European countries due to underlying health conditions, although there is considerable uncertainty in these analyses. ${ }^{33} 34$

Second, we find that the intervention strategies that have been implemented so far in Malawi would be unlikely to suppress or substantially mitigate the epidemic. Although lockdowns have been highly effective across a number of settings, they may be impractical in Malawi for a number of reasons. ${ }^{3} 3536$ Approximately $50 \%$ of the Malawian population lives in poverty, meaning there is no financial buffer if people are unable to earn money. ${ }^{3637}$ The disruptions to food production and delivery chains are likely to impact those who are most vulnerable, with food shortages likely to occur within days of lockdown being implemented.

We find that, similar to other studies, shielding of the older population (plus other vulnerable populations, such as people living with HIV or TB) would be effective in significantly reducing the death rate. ${ }^{8} 38$ The practicalities of moving elderly people into separate accommodation in the African context are uncertain at best, but it is a potentially risky strategy as a single imported case could have devastating effects. In high-income countries, this strategy has proven difficult with outbreaks occurring in many nursing homes. ${ }^{39}$ Designating shielded households, or even single rooms within a household may be a viable strategy in Malawi, which has an extensive network of community health workers who could facilitate and support such measures.

Given the difficult choices facing decision-makers in Malawi and elsewhere, it is not surprising that significant attention has turned to less disruptive strategies for restricting some population movement and advocating use of face coverings, a putatively low-cost and readily available means of reducing transmission risk. ${ }^{40}$ Delaying the epidemic by even a few months could allow time for new vaccines to be delivered and for further therapeutics to be tested and introduced. ${ }^{174142}$ Additional interventions, such as testing (test, trace and isolate) and local quarantining, could have a significant impact on the spread of infection and have been regularly used for casefinding and containment for HIV and TB in low-income and middle-income countries. ${ }^{43-46}$ However, they are extremely intensive and difficult to implement at a large scale and therefore may not be a feasible option for mitigating the outbreak in Malawi.

Third, we find that increases in certain types of capacity in the hospital may contribute to reducing deaths. The current priorities for COVID-19 response in Malawi are to distribute vaccines to health workers and significantly expand access to oxygen concentrators. ${ }^{15} 47$ There are likely to be improvements to long-term morbidity and lung health if severe cases receive oxygen when required, combined with reduced probability of requiring mechanical ventilation, although we do not capture this here. There is an urgent need for further data to analyse the longer-term impacts of COVID-19 infection to inform this. Incorporating the predicted impact of a vaccine, prioritised for health workers, is not possible using this model as we do not capture occupation-based exposure risks. WHO strongly recommends systemic corticosteroid therapy (dexamethasone) for severe COVID-19 infections, either alone or in combination with other drugs, which may reduce mortality and the need for mechanical ventilation. ${ }^{41}$ The impact of these therapies 
in sub-Saharan Africa is not yet well documented and is likely to be affected by coinfections, particularly HIV and $\mathrm{TB}$, coupled with late presentation to care.

The potential risk of nosocomial transmission is high, compounded by global shortages in personal protective equipment (PPE). ${ }^{48}$ In response, the Ministry of Health in Malawi developed COVID-19 treatment centres away from central hospitals and developed reusable PPE equipment to supplement those already acquired. ${ }^{49} \mathrm{We}$ optimistically assume here that hospitalised cases are isolated and do not contribute to onwards transmission either in the community or to healthcare workers, which may bias our estimates of disease spread. Additionally, discounting this risk lowers the expected impact of NPI. Other modelling studies have shown variable risks in within-hospital transmission, with Evans et al suggesting up to $89 \%$ of infections in healthcare workers in England were acquired within the health system and Treibel et al finding the majority of these infections were acquired through community transmission. ${ }^{450}$

The unadjusted IFR that we use to derive the mortality rates along with some key parameters including treatment outcomes rely on data from high-income and middleincome settings, which may not be directly transferable to Malawi. ${ }^{3126}$ Our results are sensitive to the assumptions inherent in these analyses and cannot yet be fully parameterised using data from African settings due to the limited numbers of cases there. Age-structured contact matrices are derived from studies in Zimbabwe, although we expect that there are unlikely to be significant differences between the two settings that would meaningfully affect the conclusions drawn. Household structure is not incorporated; therefore, we cannot adjust for increased risk of infection within households. This may be of particular importance in Malawi, where households are multigenerational and there may not be space to designate separate rooms for high-risk individuals. An important next step in this analysis would be the integration of the model with geographically disaggregated surveillance data on testing, deaths, movement and other data, which could capture local transmission and potentially open the way to more finely targeted interventions that may maximise epidemic control with lesser disruptions overall.

The estimates of relative risk of mortality with comorbidities are derived mainly from studies in high-income or upper-middle-income settings and may vary by age, although we do not capture this here. The management of comorbidities is likely to differ across settings, and so the corresponding risk of mortality with these conditions may vary also. The relative risks of death of the different comorbidities were combined in an additive model, given that the reported HRs used have been adjusted for the presence of other conditions.

The low numbers of cases reported in the first wave of the epidemic in Malawi could be consistent with a lower $R_{t}$ than is assumed here or an imperfect surveillance system with low numbers of tests being carried out. Approximately 1000 deaths have been reported throughout the whole outbreak, although this is likely an underestimate, with $82 \%$ of those occurring in $2021 .^{47}$ We estimate here approximately 80000 deaths may occur if stricter NPI are not introduced, falling to 48000 if therapeutics effectively moderate mortality rates. Introduction of a vaccine is likely to have a significant impact on the course of the epidemic and, if prioritised to those at highest risk, could substantially reduce the projected number of deaths.

This study has focused on the effects of NPI and health system capacity with respect to one disease, COVID-19. However, imposing lockdown could disrupt routine health services such as the provision of care for HIV, TB and malaria along with national immunisation programmes, compounding increases in mortality rates. Balancing the competing demands on health versus economic productivity, poverty and education is an extremely difficult decision, and we present these projections as a series of hypothetical scenarios which could be used to inform decision-making.

These outputs are not intended to be a forecast of what will happen in Malawi, and evidence should be reviewed in the light of continuously evolving surveillance data and combined with detailed analyses on the broader impacts of any potential interventions. Lessons could be learnt from the South African response, which implemented a rapid, phased strategy, successfully delaying the outbreak despite considerable challenges. In addition to physical distancing and restrictions on movement, South Africa capitalised on existing experienced teams of community health workers to conduct active case finding, along with redirecting contact-tracing teams, previously established for TB control, to conduct COVID-19 contact tracing and monitor quarantine compliance. ${ }^{44}$ Clearly, lockdown would have the biggest impact on the spread of SARS-CoV-2, but in settings where this is not feasible, a combination of interventions such as shielding, face covering, increasing hospital capacity and therapeutic agents could together have a significant impact on mortality.

\section{Twitter Timothy Colbourn @timcolbourn}

Contributors Literature search: TM, TC, AP and TH. Figures: TDM. Study design: TM, CW, OW, PW, ACG, TC, AP, TH and JM-B. Data collection: TM, CW, DN, OW, PW, ACG, TH and JM-B. Data analysis: TM, TH, AP and TC. Data interpretation: TM, CW, DN, OW, PW, ACG, PR, TC, AP, TH and JM-B. Writing: TM, CW, DN, WN, OW, PW, ACG, $\mathrm{PR}, \mathrm{TC}, \mathrm{AP}, \mathrm{TH}$ and JM-B.

Funding TM, TH, AP, TC, JM-B, PR, DN and WN are supported by UK Research and Innovation as part of the Global Challenges Research Fund (grant number MR/ P028004/1). TM, CW, PW, OW, ACG and TH acknowledge joint Centre funding from the UK Medical Research Council and Department for International Development (grant reference: MR/R015600/1). We thank the Imperial College COVID-19 Response Team for their feedback and assistance with method development. We also thank the University of Malawi Health Economics and Policy Unit Think Tank members for their support and collaboration in this project.

Competing interests None declared.

Patient consent for publication Not required.

Ethics approval Ethical approval was not required for this study, which uses publicly available, anonymised data.

Provenance and peer review Not commissioned; externally peer reviewed. 
Data availability statement Data are available in a public, open access repository. Source code and supporting documentation for the SEIR model are available online (https://github.com/mrc-ide/squire). All data used in the analyses are publicly available and sources have been listed for each.

Supplemental material This content has been supplied by the author(s). It has not been vetted by BMJ Publishing Group Limited (BMJ) and may not have been peer-reviewed. Any opinions or recommendations discussed are solely those of the author(s) and are not endorsed by BMJ. BMJ disclaims all liability and responsibility arising from any reliance placed on the content. Where the content includes any translated material, BMJ does not warrant the accuracy and reliability of the translations (including but not limited to local regulations, clinical guidelines, terminology, drug names and drug dosages), and is not responsible for any error and/or omissions arising from translation and adaptation or otherwise.

Open access This is an open access article distributed in accordance with the Creative Commons Attribution 4.0 Unported (CC BY 4.0) license, which permits others to copy, redistribute, remix, transform and build upon this work for any purpose, provided the original work is properly cited, a link to the licence is given, and indication of whether changes were made. See: https://creativecommons.org/ licenses/by/4.0/.

\section{ORCID iDs}

Tara Mangal http://orcid.org/0000-0001-9222-8632

Oliver Watson http://orcid.org/0000-0003-2374-0741

\section{REFERENCES}

1 World Health Organization. Coronavirus disease (COVID-19): situation report - 209. Geneva, Switzerland; 2020 [Accessed 16 Aug 2020].

2 Ferguson N, Laydon D, Nedjati Gilani G. Report 9: impact of nonpharmaceutical interventions (NPIs) to reduce COVID19 mortality and healthcare demand, 2020. Available: https://www.imperial.ac.uk/ media/imperial-college/medicine/sph/ide/gida-fellowships/ImperialCollege-COVID19-NPI-modelling-16-03-2020.pdf

3 Flaxman S, Mishra S, Gandy A, et al. Estimating the effects of non-pharmaceutical interventions on COVID-19 in Europe. Nature 2020;584:257-61.

4 Cowling BJ, Ali ST, Ng TWY, et al. Impact assessment of nonpharmaceutical interventions against coronavirus disease 2019 and influenza in Hong Kong: an observational study. Lancet Public Health 2020;5:e279-88.

5 Kucharski AJ, Klepac P, Conlan AJK, et al. Effectiveness of isolation, testing, contact tracing, and physical distancing on reducing transmission of SARS-CoV-2 in different settings: a mathematical modelling study. Lancet Infect Dis 2020;20:1151-60.

6 Oxford. COVID-19 government response tracker, blavatnik school of government, 2020. Available: https://www.bsg.ox.ac.uk/research/ research-projects/covid-19-government-response-tracker [Accessed 15 Mar 2021].

7 National Statistical Office, ICF. Malawi demographic and health survey 2015-2016, 2017. Available: https://dhsprogram.com/pubs/ pdf/FR319/FR319.pdf

8 Davies NG, Kucharski AJ, Eggo RM, et al. Effects of nonpharmaceutical interventions on COVID-19 cases, deaths, and demand for hospital services in the UK: a modelling study. Lancet Public Health 2020;5:e375-85.

9 Li Y, Campbell H, Kulkarni D, et al. The temporal association of introducing and lifting non-pharmaceutical interventions with the time-varying reproduction number (R) of SARS-CoV-2: a modelling study across 131 countries. Lancet Infect Dis 2021;21:193-202.

10 Karnakov P, Arampatzis G, Kičić I, et al. Data-driven inference of the reproduction number for COVID-19 before and after interventions for 51 European countries. Swiss Med Wkly 2020;150:w20313.

11 Teachout M, Zipfel C. The economic impact of COVID-19 lockdowns in sub Saharan Africa: international growth centre, 2020. Available: https://www.theigc.org/wp-content/uploads/2020/05/Teachout-andZipfel-2020-policy-brief-.pdf

12 World Health Organization. Advice on the use of masks in the context of COVID-19 Geneva, Switzerland, 2020. Available: https://apps. who.int/iris/bitstream/handle/10665/332293/WHO-2019-nCov-IPC Masks-2020.4-eng.pdf?sequence=1\&isAllowed=y [Accessed 05 Jun 2020].

13 The Royal Society. Face masks and coverings for the general public: behavioural knowledge, effectiveness of cloth coverings and public messaging. London, UK, 2020. https://royalsociety.org/-/media/
policy/projects/set-c/set-c-facemasks.pdf?la=en-GB\&hash=A22A 87CB28F7D6AD9BD93BBCBFC2BB24

14 Sonenthal PD, Masiye J, Kasomekera N, et al. COVID-19 preparedness in Malawi: a national facility-based critical care assessment. Lancet Glob Health 2020;8:e890-2.

15 UNICEF. Malawi: COVID-19 situation report No. 6 Lilongwe, Malawi, 2020. Available: https://www.unicef.org/malawi/sites/unicef. org.malawi/files/2020-05/UNICEF\%20Malawi\%20COVID-19\% 20Situation\%20Report_4\%20May\%202020\%20\%28004\%29.pdf

16 Patel BK, Kress JP, Hall JB. Alternatives to invasive ventilation in the COVID-19 pandemic. JAMA 2020;324:43-4.

17 Horby P, Lim WS, Emberson J. Effect of dexamethasone in hospitalized patients with COVID-19: preliminary report. NEJM 2020;384:693-704.

18 Horby PW, Pessoa-Amorim G, Peto L. Tocilizumab in patients admitted to hospital with COVID-19 (recovery): preliminary results of a randomised, controlled, open-label, platform trial. medRxiv 2021.

19 Banerjee A, Pasea L, Harris S, et al. Estimating excess 1-year mortality associated with the COVID-19 pandemic according to underlying conditions and age: a population-based cohort study. Lancet 2020;395:1715-25.

20 Office for National Statistics. Deaths registered Weekly in England and Wales, provisional: week ending, 2020. Available: https://www. ons.gov.uk/peoplepopulationandcommunity/healthandsocialcare/ conditionsanddiseases [Accessed 05 Jun 2020].

21 Verity R, Okell LC, Dorigatti I, et al. Estimates of the severity of coronavirus disease 2019: a model-based analysis. Lancet Infect Dis 2020;20:669-77.

22 Palaiodimos L, Kokkinidis DG, Li W, et al. Severe obesity, increasing age and male sex are independently associated with worse inhospital outcomes, and higher in-hospital mortality, in a cohort of patients with COVID-19 in the Bronx, New York. Metabolism 2020;108:154262.

23 Williamson E, Walker AJ, Bhaskaran KJ. OpenSAFELY: factors associated with COVID-19-related hospital death in the linked electronic health records of 17 million adult NHS patients. medRxiv 2020.

24 Boulle A, Davies M-A, Hussey H. Risk factors for coronavirus disease 2019 (COVID-19) death in a population cohort study from the Western Cape Province, South Africa. Clinical Infectious Diseases 2020;7.

25 Ssentongo P, Ssentongo AE, Heilbrunn ES, et al. Association of cardiovascular disease and 10 other pre-existing comorbidities with COVID-19 mortality: a systematic review and meta-analysis. PLoS One 2020;15:e0238215

26 Walker PGT, Whittaker C, Watson OJ, et al. The impact of COVID-19 and strategies for mitigation and suppression in low- and middleincome countries. Science 2020;369:413-22.

27 Melegaro A, Del Fava E, Poletti P, et al. Social contact structures and time use patterns in the Manicaland Province of Zimbabwe. PLoS One 2017;12:e0170459.

28 Imperial College London. Situation report for COVID-19: Africa, 2020-08-17, 2020. Available: https://mrc-ide.github.io/global-Imicreports/Africa/ [Accessed 20 Aug 2020].

29 Kupferschmidt K. New mutations raise specter of 'immune escape'. Science 2021;371:329-30.

30 Brazeau N, Verity R, Jenks S, Fu H, Whittaker C, Winskill P. Report 34: COVID-19 infection fatality ratio: estimates from seroprevalence; 2020.

31 Meyerowitz-Katz G, Merone L. A systematic review and metaanalysis of published research data on COVID-19 infection-fatality rates. medRxiv 2020

32 Bell D, Hansen KS, Kiragga AN, et al. Predicting the impact of COVID-19 and the potential impact of the public health response on disease burden in Uganda. Am J Trop Med Hyg 2020;103:1191-7.

33 Clark A, Jit M, Warren-Gash C, et al. Global, regional, and national estimates of the population at increased risk of severe COVID-19 due to underlying health conditions in 2020: a modelling study. Lancet Glob Health 2020;8:e1003-17.

34 Diop BZ, Ngom M, Pougué Biyong C, et al. The relatively young and rural population may limit the spread and severity of COVID-19 in Africa: a modelling study. BMJ Glob Health 2020;5:e002699.

35 Kraemer MUG, Yang C-H, Gutierrez B, et al. The effect of human mobility and control measures on the COVID-19 epidemic in China. Science 2020;368:493-7.

36 Nachega JB, Grimwood A, Mahomed H, et al. From easing Lockdowns to scaling up community-based coronavirus disease 2019 screening, testing, and contact tracing in Africa-Shared approaches, innovations, and challenges to minimize morbidity and mortality. Clin Infect Dis 2021;72:327-31. 
37 Databank. The world bank group, 2020. Available: https://data. worldbank.org/country/malawi [Accessed 10 Jul 2020].

38 van Zandvoort $\mathrm{K}$, Jarvis $\mathrm{Cl}$, Pearson CAB, et al. Response strategies for COVID-19 epidemics in African settings: a mathematical modelling study. BMC Med 2020;18:324.

39 Public Health England. Outbreaks in care homes in England, 2020. Available: https://assets.publishing.service.gov.uk/government/ uploads/system/uploads/attachment_data/file/893025/COVID19 Care_Homes_17_June.pdf

40 Ngonghala CN, Iboi E, Eikenberry S, et al. Mathematical assessment of the impact of non-pharmaceutical interventions on curtailing the 2019 novel coronavirus. Math Biosci 2020;325:108364.

41 Rochwerg B, Siemieniuk RA, Agoritsas T, et al. A living who guideline on drugs for covid-19. BMJ 2020;370:m3379.

42 The RECOVERY Collaborative Group. Dexamethasone in hospitalized patients with Covid-19. New England Journal of Medicine 2020;384:693-704.

43 Hellewell J, Abbott S, Gimma A, et al. Feasibility of controlling COVID-19 outbreaks by isolation of cases and contacts. Lancet Glob Health 2020;8:e488-96.

44 Abdool Karim SS. The South African response to the pandemic. $N$ Engl J Med 2020;382:e95.
45 Shapiro AE, Variava E, Rakgokong MH, et al. Community-Based targeted case finding for tuberculosis and HIV in household contacts of patients with tuberculosis in South Africa. Am J Respir Crit Care Med 2012;185:1110-6

46 Reddy KP, Shebl FM, Foote JHA, et al. Cost-Effectiveness of public health strategies for COVID-19 epidemic control in South Africa: a microsimulation modelling study. Lancet Glob Health 2021:9:e120-9.

47 UNICEF. Malawi COVID-19 situation report, 17 February 2021, 2021. Available: https://www.unicef.org/media/94356/file/Malawi-COVID19SitRep-17-February-2021.pdf [Accessed 15 Mar 2021].

48 Evans S, Agnew E, Vynnycky E, et al. The impact of testing and infection prevention and control strategies on within-hospital transmission dynamics of COVID-19 in English hospitals. Philos Trans $R$ Soc Lond B Biol Sci 2021;376:20200268.

49 Chaziya J, Freyne B, Lissauer S, et al. COVID-19 in Malawi: lessons in pandemic preparedness from a tertiary children's Hospital. Arch Dis Child 2021:106:238-40.

50 Treibel TA, Manisty C, Burton M, et al. COVID-19: PCR screening of asymptomatic health-care workers at London Hospital. Lancet 2020;395:1608-10. 

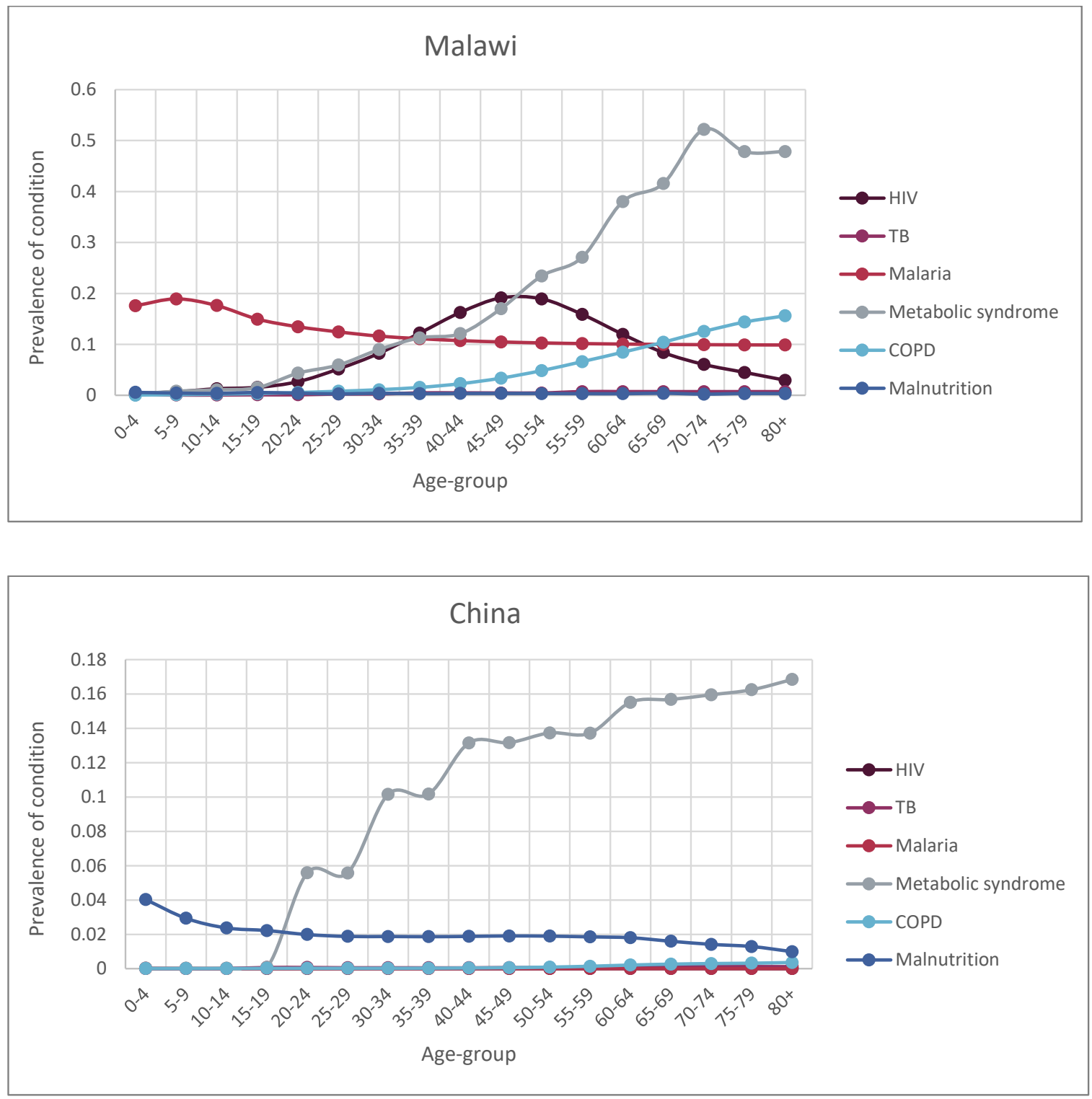

6 Supplementary Figure 1. Prevalence of key diseases in Malawi (top figure) and China (lower figure) used for

7 the estimation of country-specific infection fatality ratios. Metabolic syndrome, defined in the main text and

8 Supplementary Table 2, is a composite measure of four chronic diseases which tend to cluster in individuals. 
10 Supplementary Table 1. Prevalence data used for the calculations of disease severity and infection fatality

11 ratios.

\begin{tabular}{|c|c|c|}
\hline Data & Source & Notes \\
\hline TB & $\begin{array}{l}\text { WHO TB Report } \\
\text { (1) }\end{array}$ & $\begin{array}{l}\text { The estimated incidence of active TB in 2019: number of active cases divided by } \\
\text { population size for every age-group and by sex }\end{array}$ \\
\hline HIV & $\begin{array}{l}\text { UNAIDS Country } \\
\text { Projections } 2019 \\
\text { (2) } \\
\text { IHME } \\
\text { (3) }\end{array}$ & $\begin{array}{l}\text { For Malawi: includes all PLHIV, irrespective of treatment status. Projections are from } \\
2019 \\
\text { For China and Brazil: includes all PLHIV, irrespective of treatment status, data are } \\
\text { from } 2019\end{array}$ \\
\hline Malaria & $\begin{array}{l}\text { IHME } \\
(3)\end{array}$ & For Malawi and Brazil only. Prevalence of clinical malaria episodes in 2019. \\
\hline COPD & $\begin{array}{l}\text { IHME } \\
(3)\end{array}$ & For all countries, data from 2019 \\
\hline CVD & $\begin{array}{l}\text { IHME } \\
\text { (3) }\end{array}$ & $\begin{array}{l}\text { For all countries, data from } 2019 \\
\text { Included as part of "metabolic syndrome" }\end{array}$ \\
\hline Diabetes & $\begin{array}{l}\text { Price et al (4) } \\
\text { IHME (3) }\end{array}$ & $\begin{array}{l}\text { Included as part of "metabolic syndrome" } \\
\text { Price et al } 2018 \text { for Malawi estimates and IHME (2019) for China / Brazil estimates }\end{array}$ \\
\hline Hypertension & Price et al (4) & $\begin{array}{l}\text { Included as part of "metabolic syndrome" } \\
\text { Price et al } 2018 \text { for Malawi estimates. Hypertension is included in the CVD } \\
\text { prevalence estimates for China and Brazil. }\end{array}$ \\
\hline Obesity & $\begin{array}{l}\text { Global Obesity } \\
\text { Observatory } \\
\text { (5) }\end{array}$ & $\begin{array}{l}\text { Included as part of "metabolic syndrome" } \\
\text { Malawi data are from 2016, China data are from 2015-2019, Brazil data are from } \\
\text { 2013-2014 }\end{array}$ \\
\hline Malnutrition & $\begin{array}{l}\text { IHME } \\
(3)\end{array}$ & For all countries, data from 2019 \\
\hline $\begin{array}{l}\text { Population } \\
\text { size }\end{array}$ & $\begin{array}{l}\text { UNdata } \\
\text { (6) }\end{array}$ & For all countries, data from 2019 \\
\hline
\end{tabular}

All disease prevalence estimates are age- and sex-stratified. 


\begin{tabular}{|c|c|c|}
\hline Parameter & Value & Notes / source \\
\hline$R_{t}$ & 2 & range $1.5-2.5$ \\
\hline \multirow[t]{2}{*}{ Hospital bed capacity } & 1.3 beds per & Equates to 24,869 hospital beds. Source: World Bank (7) \\
\hline & $\begin{array}{l}1,000 \\
\text { population }\end{array}$ & \\
\hline ICU bed capacity & 25 & \\
\hline Mean latent period & 4.6 days & $\begin{array}{l}\text { Estimated at } 5.1 \text { days. The last } 0.5 \text { days are incorporated in the } \\
\text { infectious periods to capture pre-symptomatic infectivity }\end{array}$ \\
\hline Mean duration of mild infection & 2.1 days & $\begin{array}{l}\text { Incorporates } 0.5 \text { days of infectiousness prior to symptoms. In } \\
\text { combination with mean duration of severe illness this gives a mean } \\
\text { serial interval of } 6.75 \text { days }\end{array}$ \\
\hline $\begin{array}{l}\text { Mean duration of severe infection } \\
\text { prior to hospitalisation }\end{array}$ & 4.5 days & $\begin{array}{l}\text { Mean onset-to-admission of } 4 \text { days based on unpublished analysis of } \\
\text { data from the ICNARC study. Includes } 0.5 \text { days of infectiousness } \\
\text { prior to symptom onset }\end{array}$ \\
\hline $\begin{array}{l}\text { Mean duration of hospitalisation for } \\
\text { non-critical cases if survive }\end{array}$ & 9.5 days & Based on unpublished analysis of data from the ICNARC study \\
\hline $\begin{array}{l}\text { Mean duration of hospitalisation for } \\
\text { non-critical cases if die }\end{array}$ & 7.6 days & Based on unpublished analysis of data from the ICNARC study \\
\hline Mean duration in ICU if survive & 11.3 days & Based on data from the ICNARC study adjusted for censoring \\
\hline Mean duration in ICU if die & 10.1 days & Based on data from the ICNARC study adjusted for censoring. \\
\hline Mean duration in recovery after ICU & 3.4 days & Based on unpublished analysis of data from the ICNARC study \\
\hline $\begin{array}{l}\text { Relative risk of mortality for patients } \\
\text { with HIV* }\end{array}$ & $1.70-2.70$ & $\begin{array}{l}\text { Samples are drawn from the uniform distribution using the range } \\
\text { defined as lower and upper bounds (8) }\end{array}$ \\
\hline $\begin{array}{l}\text { Relative risk of mortality for patients } \\
\text { with TB }\end{array}$ & $1.81-4.04$ & $\begin{array}{l}\text { Samples are drawn from the uniform distribution using the range } \\
\text { defined as lower and upper bounds (8) }\end{array}$ \\
\hline $\begin{array}{l}\text { Relative risk of mortality for patients } \\
\text { with malaria }\end{array}$ & $1.0-3.0$ & $\begin{array}{l}\text { Assumed values. Samples are drawn from the uniform distribution } \\
\text { using the range defined as lower and upper bounds }\end{array}$ \\
\hline $\begin{array}{l}\text { Relative risk of mortality for patients } \\
\text { with COPD }\end{array}$ & $0.77-4.24$ & $\begin{array}{l}\text { Samples are drawn from the uniform distribution using the range } \\
\text { defined as lower and upper bounds }(9,10)\end{array}$ \\
\hline $\begin{array}{l}\text { Relative risk of mortality for patients } \\
\text { with malnutrition }\end{array}$ & $1.0-3.0$ & $\begin{array}{l}\text { Assumed values. Samples are drawn from the uniform distribution } \\
\text { using the range defined as lower and upper bounds }\end{array}$ \\
\hline $\begin{array}{l}\text { Relative risk of mortality for patients } \\
\text { with "metabolic syndrome" }\end{array}$ & $1.02-5.26$ & $\begin{array}{l}\text { Samples are drawn from the uniform distribution using the range } \\
\text { defined as lower and upper bounds. The range is defined using the } \\
\text { lower and upper limits from the estimated values below. }\end{array}$ \\
\hline $\begin{array}{l}\text { Relative risk of mortality for } \\
\text { patients with cardiovascular } \\
\text { disease }\end{array}$ & $1.20-5.26$ & Used to inform the combined "metabolic syndrome" risk $(9,10)$ \\
\hline $\begin{array}{l}\text { Relative risk of mortality for } \\
\text { patients with hypertension }\end{array}$ & $1.09-1.57$ & Used to inform the combined "metabolic syndrome" risk (8) \\
\hline $\begin{array}{l}\text { Relative risk of mortality for } \\
\text { patients with obesity }\end{array}$ & $1.10-4.34$ & Used to inform the combined "metabolic syndrome" risk (9) \\
\hline $\begin{array}{l}\text { Relative risk of mortality for } \\
\text { patients with diabetes }\end{array}$ & $1.02-2.84$ & Used to inform the combined "metabolic syndrome" risk $(9,10)$ \\
\hline
\end{tabular}


Estimates of disease severity

Following Walker et al., we distinguish three levels of disease severity for COVID-19: (i) those that do not require hospitalisation; (ii) those that do require hospitalisation but not intensive care; (iii) those that require intensive care (ICU).(11) Two parameters govern the proportions in each category: the proportion of infected cases requiring hospitalisation (p_severe) and the proportion of hospitalised cases requiring ICU ( $\left.p \_c r i t i c a l\right)$. We use the distributions of sampled adjusted IFR for Malawi, detailed in Methods Section 1 (i) which assume no health system constraints, as bounds for rejection sampling to determine reasonable values for these two parameters.

We sampled from a credible range for each parameter (detailed in Supplementary Table 3) based on values observed in high-income settings, keeping the age-distribution consistent with that reported in Verity et al and Walker et al.(11,12) As we have based the calculation of IFR so far on data from China, we assumed that all persons that needed hospitalisation or intensive care received it, and that the proportion of those requiring intensive care that die, $m$, is $50 \%$. This is a generalised assumption which incorporates both the availability of treatment and the mortality rates across both the untreated and treated critical cases. We assume no mortality in severe cases in this instance, although this assumption is changed in the simulation model. Combining the assumptions together, gives an overall IFR across the 17 age-groups as follows, where prop $_{a}$ is the proportion of the population in age-group $a$ :

$I_{h}=\sum_{a=1}^{17}\left(p_{-}\right.$severe $_{h, a} * p_{-}$critical $\left._{h, a} * m\right) * \operatorname{prop}_{a}$

Parameter sets for $p \_s e v e r e$ and $p \_c r i t i c a l$ were accepted if the resulting overall IFR fell within the 95\% uncertainty interval of the adjusted IFR for Malawi and the process was repeated until 1000 accepted parameter sets were generated. The resulting parameter sets were used as inputs to the epidemic simulation model. 
40 Supplementary Table 3. Estimates of disease severity for the Malawian population

\begin{tabular}{|c|c|c|c|c|}
\hline \multirow{2}{*}{$\begin{array}{l}\text { Age-group } \\
\text { (years) }\end{array}$} & \multicolumn{2}{|c|}{ Proportion cases requiring hospitalisation } & \multicolumn{2}{|c|}{ Proportion hospitalised cases requiring ICU } \\
\hline & Credible range & $\begin{array}{l}\text { Median accepted values } \\
\left(2.5^{\text {th }} \text { and } 97.5^{\text {th }} \text { quantiles }\right) *\end{array}$ & Credible range & $\begin{array}{l}\text { Median accepted values } \\
\left(2.5^{\text {th }} \text { and } 97.5^{\text {th }} \text { quantiles }\right) *\end{array}$ \\
\hline $0-4$ & $0.0002-0.0050$ & $\begin{array}{l}0.0013 \\
(0.0005-0.0029)\end{array}$ & $0.0100-0.2500$ & $\begin{array}{l}0.0636 \\
(0.0222-0.1456)\end{array}$ \\
\hline $5-9$ & $0.0002-0.0050$ & $\begin{array}{l}0.0013 \\
(0.0005-0.0029)\end{array}$ & $0.0100-0.2500$ & $\begin{array}{l}0.0636 \\
(0.0222-0.1456)\end{array}$ \\
\hline $10-14$ & $0.0002-0.0050$ & $\begin{array}{l}0.0013 \\
(0.0005-0.0029)\end{array}$ & $0.0100-0.2500$ & $\begin{array}{l}0.0636 \\
(0.0222-0.1456)\end{array}$ \\
\hline $15-19$ & $0.0004-0.0100$ & $\begin{array}{l}0.0027 \\
(0.0010-0.0058)\end{array}$ & $0.0100-0.2500$ & $\begin{array}{l}0.0636 \\
(0.0222-0.1456)\end{array}$ \\
\hline $20-24$ & $0.0010-0.0250$ & $\begin{array}{l}0.0067 \\
(0.0026-0.0145)\end{array}$ & $0.0100-0.2500$ & $\begin{array}{l}0.0636 \\
(0.0222-0.1456)\end{array}$ \\
\hline $25-29$ & $0.0020-0.0500$ & $\begin{array}{l}0.0134 \\
(0.0051-0.0290)\end{array}$ & $0.0100-0.2500$ & $\begin{array}{l}0.0636 \\
(0.0222-0.1456)\end{array}$ \\
\hline $30-34$ & $0.0032-0.0800$ & $\begin{array}{l}0.0215 \\
(0.0082-0.0464)\end{array}$ & $0.0100-0.2500$ & $\begin{array}{l}0.0636 \\
(0.0222-0.1456)\end{array}$ \\
\hline $35-39$ & $0.0046-0.1150$ & $\begin{array}{l}0.0309 \\
(0.0118-0.0668)\end{array}$ & $0.0106-0.2650$ & $\begin{array}{l}0.0674 \\
(0.0236-0.1543)\end{array}$ \\
\hline $40-44$ & $0.0058-0.1450$ & $\begin{array}{l}0.0389 \\
(0.0148-0.0842)\end{array}$ & $0.0120-0.3000$ & $\begin{array}{l}0.0763 \\
(0.0267-0.1747)\end{array}$ \\
\hline $45-49$ & $0.0078-0.1950$ & $\begin{array}{l}0.0523 \\
(0.0200-0.1132)\end{array}$ & $0.0150-0.3750$ & $\begin{array}{l}0.0954 \\
(0.0334-0.2183)\end{array}$ \\
\hline $50-54$ & $0.0116-0.2900$ & $\begin{array}{l}0.0778 \\
(0.0297-0.1684)\end{array}$ & $0.0208-0.5200$ & $\begin{array}{l}0.1323 \\
(0.0463-0.3028)\end{array}$ \\
\hline $55-59$ & $0.0144-0.3600$ & $\begin{array}{l}0.0966 \\
(0.0369-0.2090)\end{array}$ & $0.0298-0.7450$ & $\begin{array}{l}0.1895 \\
(0.0663-0.4338)\end{array}$ \\
\hline $60-64$ & $0.0204-0.5100$ & $\begin{array}{l}0.1369 \\
(0.0522-0.2961)\end{array}$ & $0.0448-1.1200$ & $\begin{array}{l}0.2849 \\
(0.0996-0.6521)\end{array}$ \\
\hline $65-69$ & $0.0234-0.5850$ & $\begin{array}{l}0.1570 \\
(0.0599-0.3396)\end{array}$ & $0.0614-1.5350$ & $\begin{array}{l}0.3905 \\
(0.1366-0.8938)\end{array}$ \\
\hline $70-74$ & $0.0292-0.7300$ & $\begin{array}{l}0.1960 \\
(0.0747-0.4238)\end{array}$ & $0.0772-1.9300$ & $\begin{array}{l}0.4909 \\
(0.1717-1.0000)\end{array}$ \\
\hline $75-79$ & $0.0354-0.8850$ & $\begin{array}{l}0.2376 \\
(0.0906-0.5138)\end{array}$ & $0.0922-2.3050$ & $\begin{array}{l}0.5863 \\
(0.2051-1.0000)\end{array}$ \\
\hline $80+$ & $0.0360-0.9000$ & $\begin{array}{l}0.2416 \\
(0.0921-0.5225)\end{array}$ & $0.1418-3.5450$ & $\begin{array}{l}0.9018 \\
(0.3154-1.000)\end{array}$ \\
\hline
\end{tabular}

\section{* distributions obtained through rejection sampling.}

42 
43 Supplementary Table 4. Social contact matrix between age-groups in Zimbabwe

\begin{tabular}{|c|c|c|c|c|c|c|c|c|c|c|c|c|c|c|c|c|}
\hline $\begin{array}{l}\text { Age- } \\
\text { group }\end{array}$ & $0-4$ & $5-9$ & $\begin{array}{l}10- \\
14\end{array}$ & $\begin{array}{l}15- \\
19\end{array}$ & $\begin{array}{l}20- \\
24\end{array}$ & $\begin{array}{l}25- \\
29\end{array}$ & $\begin{array}{l}30- \\
34\end{array}$ & $\begin{array}{l}35- \\
39\end{array}$ & $\begin{array}{l}40- \\
44\end{array}$ & $\begin{array}{l}45- \\
49\end{array}$ & $\begin{array}{l}50- \\
54\end{array}$ & $\begin{array}{l}55- \\
59\end{array}$ & $\begin{array}{l}60- \\
64\end{array}$ & $\begin{array}{l}65- \\
69\end{array}$ & $\begin{array}{l}70- \\
74\end{array}$ & $75+$ \\
\hline $0-4$ & 1.006 & 1.030 & 0.883 & 0.732 & 0.647 & 0.712 & 0.645 & 0.463 & 0.289 & 0.214 & 0.211 & 0.215 & 0.179 & 0.121 & 0.075 & 0.048 \\
\hline 5-9 & 0.807 & 2.863 & 2.668 & 0.968 & 0.423 & 0.449 & 0.468 & 0.416 & 0.289 & 0.212 & 0.182 & 0.186 & 0.177 & 0.140 & 0.093 & 0.066 \\
\hline $\begin{array}{l}10- \\
14\end{array}$ & 0.659 & 2.544 & 3.766 & 1.865 & 0.580 & 0.413 & 0.452 & 0.536 & 0.375 & 0.251 & 0.207 & 0.208 & 0.193 & 0.177 & 0.136 & 0.096 \\
\hline $\begin{array}{l}15- \\
19\end{array}$ & 0.617 & 1.041 & 2.104 & 2.548 & 1.070 & 0.575 & 0.536 & 0.645 & 0.441 & 0.297 & 0.267 & 0.264 & 0.229 & 0.225 & 0.182 & 0.112 \\
\hline $\begin{array}{l}20- \\
24\end{array}$ & 0.947 & 0.790 & 1.135 & 1.858 & 1.363 & 0.969 & 0.752 & 0.723 & 0.474 & 0.363 & 0.333 & 0.310 & 0.281 & 0.254 & 0.199 & 0.123 \\
\hline $\begin{array}{l}25- \\
29\end{array}$ & 1.091 & 0.878 & 0.848 & 1.046 & 1.014 & 1.131 & 0.885 & 0.707 & 0.425 & 0.330 & 0.297 & 0.299 & 0.271 & 0.225 & 0.153 & 0.101 \\
\hline $\begin{array}{l}30- \\
34\end{array}$ & 1.268 & 1.175 & 1.191 & 1.252 & 1.010 & 1.136 & 1.119 & 1.032 & 0.593 & 0.405 & 0.356 & 0.364 & 0.341 & 0.249 & 0.164 & 0.102 \\
\hline $\begin{array}{l}40- \\
44\end{array}$ & 0.960 & 1.225 & 1.668 & 1.738 & 1.076 & 0.923 & 1.001 & 1.192 & 0.863 & 0.629 & 0.488 & 0.434 & 0.378 & 0.311 & 0.207 & 0.117 \\
\hline $\begin{array}{l}45- \\
49\end{array}$ & 0.796 & 1.007 & 1.248 & 1.312 & 0.922 & 0.801 & 0.766 & 0.856 & 0.704 & 0.549 & 0.446 & 0.383 & 0.352 & 0.298 & 0.215 & 0.120 \\
\hline $\begin{array}{l}50- \\
54\end{array}$ & 0.844 & 0.928 & 1.106 & 1.266 & 0.909 & 0.774 & 0.722 & 0.796 & 0.587 & 0.479 & 0.417 & 0.407 & 0.397 & 0.331 & 0.242 & 0.159 \\
\hline $\begin{array}{l}55- \\
59\end{array}$ & 0.902 & 0.993 & 1.163 & 1.312 & 0.888 & 0.818 & 0.776 & 0.812 & 0.547 & 0.431 & 0.426 & 0.483 & 0.484 & 0.382 & 0.281 & 0.210 \\
\hline $\begin{array}{l}60- \\
64\end{array}$ & 0.823 & 1.041 & 1.191 & 1.250 & 0.882 & 0.815 & 0.797 & 0.781 & 0.524 & 0.435 & 0.457 & 0.532 & 0.567 & 0.449 & 0.347 & 0.259 \\
\hline $\begin{array}{l}65- \\
69\end{array}$ & 0.695 & 1.026 & 1.357 & 1.534 & 0.995 & 0.841 & 0.725 & 0.751 & 0.537 & 0.459 & 0.475 & 0.524 & 0.560 & 0.471 & 0.372 & 0.333 \\
\hline $\begin{array}{l}70- \\
74\end{array}$ & 0.592 & 0.943 & 1.442 & 1.712 & 1.080 & 0.791 & 0.664 & 0.668 & 0.495 & 0.458 & 0.481 & 0.532 & 0.599 & 0.515 & 0.455 & 0.383 \\
\hline
\end{tabular}

44 Values are estimated number of contacts between persons in each age-group per day. The contact matrix is

45 adjusted to give age-specific contact rates.(13)

46 
48 Supplementary Table 5. Age-dependent mortality rates in severe and critical cases.

\begin{tabular}{l|ll|ll}
\hline & Severe cases & & Critical cases & \\
\hline Age-group & $\begin{array}{l}\text { Probability death } \\
\text { with treatment }\end{array}$ & $\begin{array}{l}\text { Probability death } \\
\text { no treatment }\end{array}$ & $\begin{array}{l}\text { Probability death } \\
\text { with treatment }\end{array}$ & $\begin{array}{l}\text { Probability death } \\
\text { no treatment }\end{array}$ \\
\hline $0-4$ & 0.013 & 0.6 & 0.5 & 0.95 \\
$5-9$ & 0.013 & 0.6 & 0.5 & 0.95 \\
$10-14$ & 0.013 & 0.6 & 0.5 & 0.95 \\
$15-19$ & 0.013 & 0.6 & 0.5 & 0.95 \\
$20-24$ & 0.013 & 0.6 & 0.5 & 0.95 \\
$25-29$ & 0.013 & 0.6 & 0.5 & 0.95 \\
$30-34$ & 0.013 & 0.6 & 0.5 & 0.95 \\
$35-39$ & 0.013 & 0.6 & 0.5 & 0.95 \\
$40-44$ & 0.015 & 0.6 & 0.5 & 0.95 \\
$45-49$ & 0.019 & 0.6 & 0.5 & 0.95 \\
$50-54$ & 0.027 & 0.6 & 0.5 & 0.95 \\
$55-59$ & 0.042 & 0.6 & 0.5 & 0.95 \\
$60-64$ & 0.069 & 0.6 & 0.5 & 0.95 \\
$65-69$ & 0.105 & 0.6 & 0.5 & 0.95 \\
$70-74$ & 0.149 & 0.6 & 0.5 & 0.95 \\
$75-79$ & 0.203 & 0.6 & 0.5 & 0.95 \\
$80+$ & 0.580 & 0.6 & & 0.95 \\
\hline
\end{tabular}

49 The probabilities of death are the default values used in the COVID-19 Global Model of Walker et al.(11)

50 Values were derived using data from the ICNARC study in the UK.(14) 
53

54

55

56

57

58

59

60

61

62

63

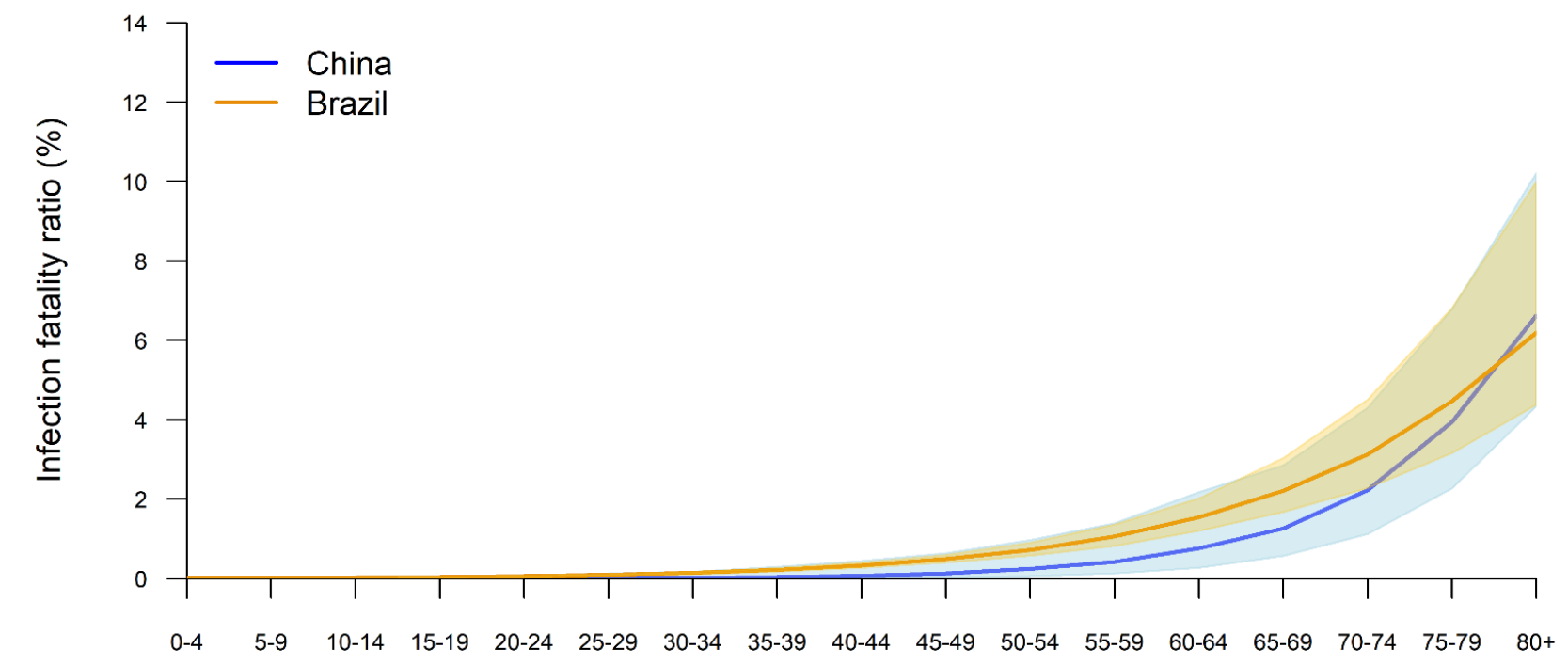

64

65

66

Estimates of infection fatality ratios in Malawi

The approach detailed in the main manuscript, using age-specific infection fatality ratios (IFR) from China and adjusting for the demography and comorbidity prevalence in Malawi, was repeated using estimates of IFR from Brazil to determine whether the choice of primary data on which to base this analysis significantly impacted the predicted values for Malawi.(15) The figure below (Supplementary Figure 1) shows the adjusted estimates of IFR by age in a theoretical population with no comorbidities using the data reported from China early in the pandemic and the more recent model estimated values from Brazil which incorporate seroreversion.(12) The median adjusted IFR for a population with no comorbidities is slightly higher when using the Brazil data, although the uncertainty intervals overlap for every age-group. When using the Brazil data, the adjusted population-weighted IFR for Malawi assuming no health system constraints is $0.48 \%$ (95\% uncertainty interval [UI] $0.33-0.64 \%$ ), compared with $0.26 \%$ (95\% UI $0.12-0.69 \%$ ) when using the Chinese data.

Age-group

Supplementary Figure 2. Infection fatality ratios in a theoretical population assuming no comorbidities.

Estimates are derived from data reported for China (blue) and Brazil (orange). 


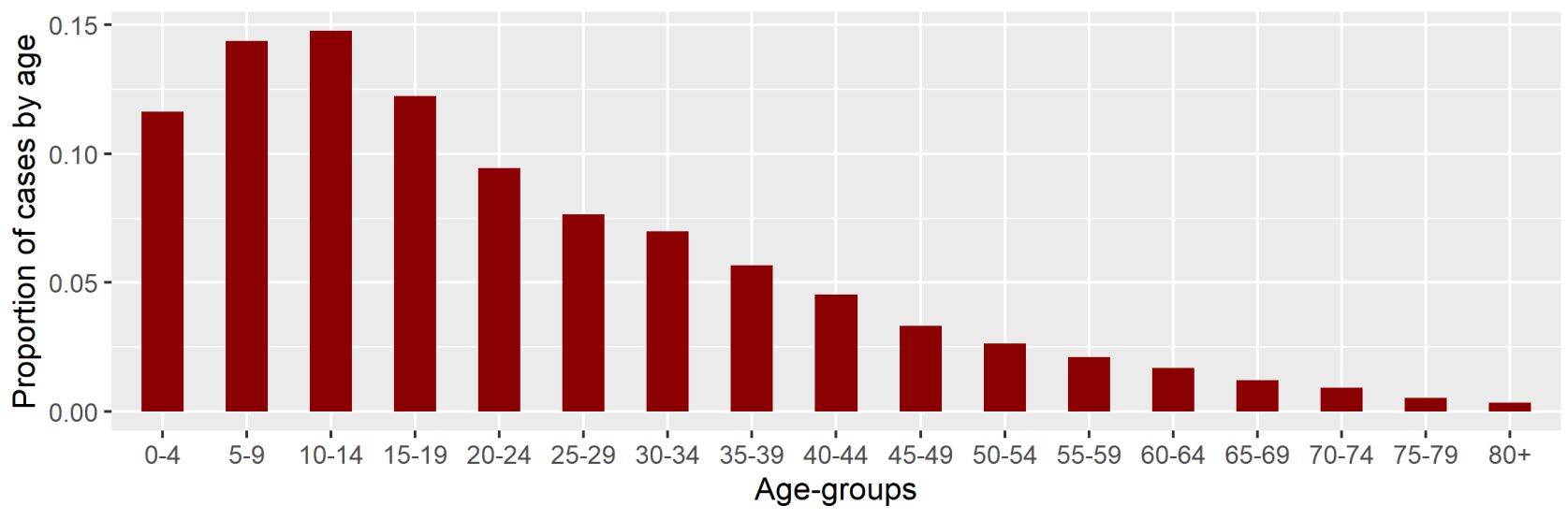

Supplementary Figure 3. Age distribution of infected cases (asymptomatic and symptomatic) at the peak of the projected unmitigated epidemic. 


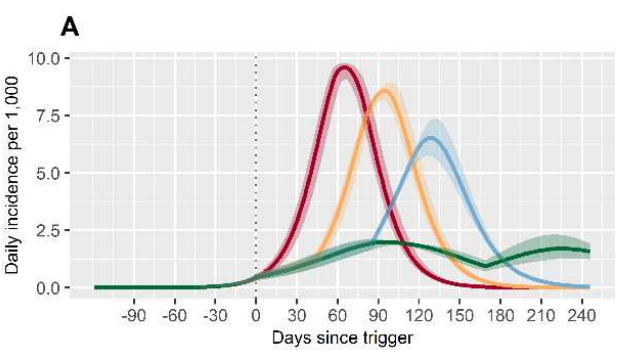

C

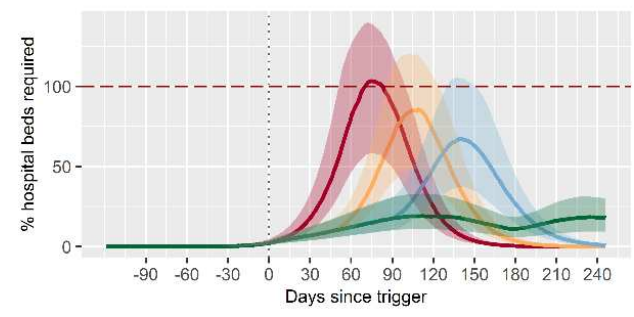

B
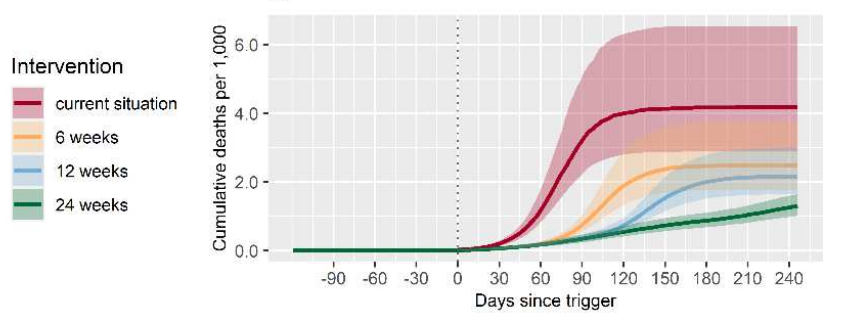

Intervention

- current situation

6 weeks

- 12 weeks

24 weeks

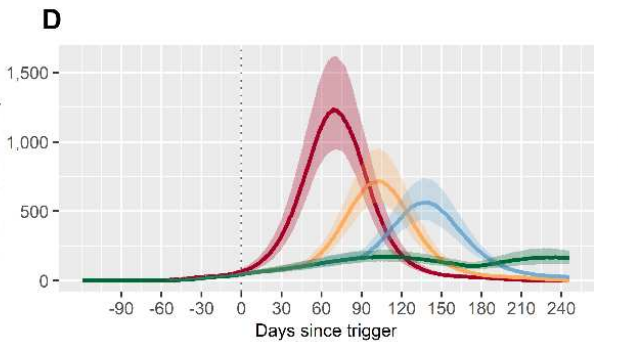

Intervention
$-\quad$ current situation
-6 weeks
-12 weeks
$-\quad 24$ weeks

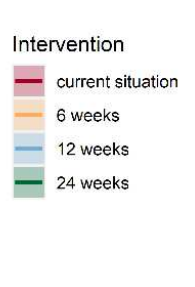

74

75

76

77

78

79

80

82

81 the capacity of the health system for non-intensive care (C).

Supplementary Figure 4. Impact of changing the duration of lockdown compared with the current situation on

the daily incidence per 1,000 population (A), the cumulative deaths per 1,000 population (B), the percentage of

7 hospital beds that are required (C) and the number of ICU beds that are required (D). The current situation

8 reflects the non-pharmaceutical interventions adopted by Malawi at the start of the second wave. Each

9 intervention represents the implementation of lockdown over 6,12 or 24 weeks. The trigger date (1 death per

100,000 population per week) is shown with a vertical grey dashed line. The red horizontal dashed line shows 
83 Supplementary Table 6. Simulation outputs under different assumptions of $R_{0}$.

\begin{tabular}{|c|c|c|c|c|c|}
\hline & & Baseline & Current situation & Enhanced shielding & Lockdown \\
\hline \multirow[t]{4}{*}{$R_{t}=1.5$} & Total cases / 1,000 & $\begin{array}{l}563.1 \\
(469.8-657.9) \\
\end{array}$ & $\begin{array}{l}21.7 \\
(11-33.9)\end{array}$ & $\begin{array}{l}19.6 \\
(9.6-31.7) \\
\end{array}$ & $\begin{array}{l}18 \\
(9.3-28.9)\end{array}$ \\
\hline & Number hospital beds required at peak & $\begin{array}{l}25,100 \\
(13,700-33,800)\end{array}$ & $\begin{array}{l}1,000 \\
(500-2,000)\end{array}$ & $\begin{array}{l}700 \\
(300-1,400)\end{array}$ & $\begin{array}{l}700 \\
(300-1,400)\end{array}$ \\
\hline & Number ICU beds required at peak & $\begin{array}{l}1,200 \\
(900-1,500)\end{array}$ & $\begin{array}{l}100 \\
(100-100)\end{array}$ & $\begin{array}{l}100 \\
(0-100)\end{array}$ & $\begin{array}{l}100 \\
(0-100)\end{array}$ \\
\hline & Total number of deaths / 1000 & $\begin{array}{l}4 \\
(2.8-6.3) \\
\end{array}$ & $\begin{array}{l}0.1 \\
(0.1-0.2) \\
\end{array}$ & $\begin{array}{l}0.1 \\
(0-0.2) \\
\end{array}$ & $\begin{array}{l}0.1 \\
(0-0.2) \\
\end{array}$ \\
\hline \multirow[t]{4}{*}{$R_{t}=\mathbf{2 . 0}$} & Total cases / 1,000 & $\begin{array}{l}769.7 \\
(668.4-872.6)\end{array}$ & $\begin{array}{l}575.3 \\
(483.1-667.4)\end{array}$ & $\begin{array}{l}499.8 \\
(412.4-591.4)\end{array}$ & $\begin{array}{l}275.0 \\
(223.6-326.9)\end{array}$ \\
\hline & Number hospital beds required at peak & $\begin{array}{l}40,700 \\
(28,000-59,700)\end{array}$ & $\begin{array}{l}25,700 \\
(14,500-34,800)\end{array}$ & $\begin{array}{l}17,300 \\
(9,800-26,400)\end{array}$ & $\begin{array}{l}5,700 \\
(3,100-9,900)\end{array}$ \\
\hline & Number ICU beds required at peak & $\begin{array}{l}2,600 \\
(2,000-3,400)\end{array}$ & $\begin{array}{l}1,200 \\
(900-1,600)\end{array}$ & $\begin{array}{l}600 \\
(400-700)\end{array}$ & $\begin{array}{l}300 \\
(200-400)\end{array}$ \\
\hline & Total number of deaths / 1000 & $\begin{array}{l}7.0 \\
(4.3-11.6) \\
\end{array}$ & $\begin{array}{l}4.2 \\
(2.9-6.5)\end{array}$ & $\begin{array}{l}2.1 \\
(1.6-2.9)\end{array}$ & $\begin{array}{l}1.8 \\
(1.4-2.2)\end{array}$ \\
\hline \multirow[t]{4}{*}{$R_{t}=2.5$} & Total cases / 1,000 & $\begin{array}{l}867.8 \\
(764.3-972.6) \\
\end{array}$ & $\begin{array}{l}740.8 \\
(638.8-843.1)\end{array}$ & $\begin{array}{l}689.4 \\
(593.5-788.6)\end{array}$ & $\begin{array}{l}535.5 \\
(458.5-613.6) \\
\end{array}$ \\
\hline & Number hospital beds required at peak & $\begin{array}{l}53,300 \\
(35,000-80,200)\end{array}$ & $\begin{array}{l}37,900 \\
(26,500-54,800)\end{array}$ & $\begin{array}{l}31,700 \\
(21,600-43,000)\end{array}$ & $\begin{array}{l}23,100 \\
(12,500-31,800)\end{array}$ \\
\hline & Number ICU beds required at peak & $\begin{array}{l}3,700 \\
(2,900-5,000)\end{array}$ & $\begin{array}{l}2,300 \\
(1,800-3,100)\end{array}$ & $\begin{array}{l}1,300 \\
(1,000-1,700)\end{array}$ & $\begin{array}{l}1,100 \\
(800-1,400)\end{array}$ \\
\hline & Total number of deaths / 1000 & $\begin{array}{l}8.7 \\
(5.4-14)\end{array}$ & $\begin{array}{l}6.5 \\
(4.0-10.9)\end{array}$ & $\begin{array}{l}4.0 \\
(2.6-7.0)\end{array}$ & $\begin{array}{l}3.7 \\
(2.7-5.6)\end{array}$ \\
\hline
\end{tabular}

All values are medians of 1000 simulations using the sampled parameter sets. Numbers of hospital beds, ICU

beds and deaths are rounded to the nearest 100. The trigger day for interventions (1.0 death per 100,000

population per week) is day 341,120 , and 81 for $R_{t}=1.5,2.0$ and 2.5 respectively.

87 
94 Supplementary Table 7. Projected cumulative number of deaths with increases in hospital capacity.

\begin{tabular}{|l|l|}
\hline Intervention & Total deaths per $\mathbf{1 , 0 0 0}$ population \\
\hline Current capacity & 4.2 \\
& $(2.9-6.5)$ \\
\hline Increase capacity by $\mathbf{2 5 \%}$ & 3.9 \\
& $(2.8-5.7)$ \\
\hline Increase capacity by $\mathbf{5 0 \%}$ & 3.7 \\
& $(2.8-5.3)$ \\
\hline Increase capacity by $\mathbf{7 5 \%}$ & 3.6 \\
& $(2.8-5.0)$ \\
\hline Increase capacity by $\mathbf{1 0 0 \%}$ & 3.5 \\
& $(2.8-4.7)$ \\
\hline
\end{tabular}

95 


\section{References}

1. WHO TB burden estimates [Internet]. 2020 [cited 2nd March 2021]. Available from: https://www.who.int/tb/country/data/download/en/.

2. AIDSInfo [Internet]. 2020 [cited 22nd May 2020]. Available from: https://aidsinfo.unaids.org/.

3. Global Burden of Disease Study 2019 (GBD 2019) Results [Internet]. Institute for Health Metrics and Evaluation (IHME). 2018 [cited 2nd March 2021]. Available from: http://ghdx.healthdata.org/gbd-results-tool.

4. Price AJ, Crampin AC, Amberbir A, Kayuni-Chihana N, Musicha C, Tafatatha T, et al. Prevalence of obesity, hypertension, and diabetes, and cascade of care in sub-Saharan Africa: a cross-sectional, population-based study in rural and urban Malawi. The Lancet Diabetes \& endocrinology. 2018;6(3):208-22.

5. Global Obesity Observatory [Internet]. 2020 [cited 10th June 2020]. Available from: https://www.worldobesitydata.org/.

6. Population by age, sex and urban/rural residence [Internet]. 2020 [cited 22nd May 2020]. Available from: http://data.un.org/Data.aspx?d=POP\&f=tableCode\%3a22.

7. World Bank Open Data [Hospital beds per 1,000 people] [Internet]. 2020 [cited 16th June 2020]. Available from: https://databank.worldbank.org/home.aspx.

8. Boulle A, Davies M-A, Hussey H, Ismail M, Morden E, Vundle Z, et al. Risk factors for COVID-19 death in a population cohort study from the Western Cape Province, South Africa. Clinical infectious diseases. 2020;Online ahead of print.

9. Noor FM, Islam MM. Prevalence and Associated Risk Factors of Mortality Among COVID-19 Patients: A MetaAnalysis. Journal of Community Health. 2020;45(6):1270-82.

10. Ssentongo P, Ssentongo AE, Heilbrunn ES, Ba DM, Chinchilli VM. Association of cardiovascular disease and 10 other pre-existing comorbidities with COVID-19 mortality: A systematic review and meta-analysis. PloS one. 2020;15(8):e0238215.

11. Walker PGT, Whittaker C, Watson OJ, Baguelin M, Winskill P, Hamlet A, et al. The impact of COVID-19 and strategies for mitigation and suppression in low- and middle-income countries. Science. 2020;369(6502):413-22.

12. Verity R, Okell LC, Dorigatti I, Winskill P, Whittaker C, Imai N, et al. Estimates of the severity of coronavirus disease 2019: a model-based analysis. The Lancet Infectious Diseases. 2020;20(6):669-77.

13. Melegaro A, Del Fava E, Poletti P, Merler S, Nyamukapa C, Williams J, et al. Social contact structures and time use patterns in the Manicaland Province of Zimbabwe. PloS one. 2017;12(1).

14. Intensive Care National Audit \& Research Centre. ICNARC report of COVID-19 in critical care2020 1st July 2020. Available from: https://www.icnarc.org/.

15. Brazeau N, Verity R, Jenks S, Fu H, Whittaker C, Winskill P, et al. Report 34: COVID-19 infection fatality ratio: estimates from seroprevalence. 2020. 